\title{
Effect of Artificial Photoperiod Program on the Maturation Stages of Gilthead Sea Bream (Sparus Aurata) \\ M.F. Badran ${ }^{1}$, M.A. El-Danasoury ${ }^{2}$, Safaa M. Sharaf ${ }^{2}$ and A. M. Hassan $^{3}$
}

1-Aquatic hatchery production department, Fish farming and technology institute, Suez Canal University. 2-Department of animal production and fish resources, Faculty of Agriculture, Suez Canal University. 3-Department of Animal Hygiene, Zoonoses and Behaviour, Faculty of Veterinary Medicine,

Suez Canal University.

\begin{abstract}
:
Photoperiod is one of the most important factors driving sexual maturation in fish. This study showed the effect of artificial photoperiod program on the maturation stages of Gilthead Sea bream in captivity. A total number of 78 Gilthead Sea bream (Sparus aurata) broodstock (48 male and 30 female) of $295.56 \mathrm{~g}$ and 332.03 g average body weight, respectively, fishes were collected and kept in indoor fiber circular tanks filled with salt water and under controlled photoperiods. They were divided into 2 groups. The first group was exposed to water temperature $22 \pm 1^{\circ} \mathrm{C}$, natural photoperiod and natural light intensity (control). Fish of the second group was kept at water temperature $22 \pm 1^{\circ} \mathrm{C}$ and exposed to artificial photoperiod program with 600 lux light intensity. The experiment was conducted for 4 months. At the end of every month Gonadosomatic Index (GSI \%) and histological sections were done. Results showed that GSI value was highest in second group after the third month in female and in second month in male when compared to fish in the control group. The histological sections confirmed these results. It could be concluded that photoperiod program is an initiative for reproductive cycle and gonadal maturation but it couldn't reach the final maturity and can induce spawning of gilthead sea bream in captivity.
\end{abstract}

Key words: Gilthead Sea bream, Maturation stages, Artificial Photoperiod, Sparus aurata

\section{Introduction}

The Gilthead Sea bream (Sparus aurata) is one of the most important marine fish in fisheries and aquaculture especially in the Mediterranean area (FAO, 1999). This type of fish is hermaphrodite and is functional as male in the first 2 years and at sizes over $30 \mathrm{~cm}$ most of fishes become females. (Arabaci and Yilmaz, 2010).

A sustainable aquaculture industry is the captivity to enhance reproduction processes of fish in 
captivity and to acquire high quality seed in future. Aquaculture production and development is based on the management of aquaculture reproduction. Reproduction in fishes is regulated by the external environmental factors that trigger internal mechanisms into action (Yousefian and Mousavi, 2011).

There is lack of information about different fish species reproduction in captivity, therefore the present study aimed to evaluate the role of artificial photoperiod program on the maturation stages of gilthead sea bream in captivity through determination of GSI as well as gonadal histological sections in both male and female.

\section{Materials and Methods}

A total number of 78 (48 male and 30 female) Gilthead Sea Bream $S$. aurata broodstocks were collected from Manzala Lake, Damiatta Governorate and Suez Canal Company for Fish Farming and Aquaculture at Ismailia Governorate, Egypt. They were transported to Fish Farming and Technology institute, Suez Canal University, Ismailia Governorate, Egypt. Average body weight were $295.56 \mathrm{~g}$ and $332.03 \mathrm{~g}$ for males and females, respectively. Fish were kept in indoor fiber circular holding tanks with maximum capacity of 3 $\mathrm{m}^{3}$ (1.7 $\mathrm{m}$ diameter and $1.4 \mathrm{~m}$ high) filled with salt water, under controlled photoperiods.
The brood stock was manually fed once daily (3\% of body weight) with minced pieces of squad, mackerel, sardine, shrimp and small fish.

Broodstocks were divided into two groups (three replicates/group). Each replicate consists of 8 males and 5 females:

The first group $\left(\mathrm{T}_{1}-\right.$ control) of broodstocks were exposed to water temperature of $22 \pm 1^{\circ} \mathrm{C}$, natural photoperiod and natural light intensity. They were kept near large windows to let direct sunlight rolling on the tanks.

The second group $\left(\mathrm{T}_{2}\right.$ - treated) Broodstocks were kept at water temperature range from $22 \pm 1^{\circ} \mathrm{C}$ and exposed to artificial photoperiod program (Table 1) and light intensity in the range of 600 lux and measured by Light meter (YK-10LX, Taiwan), which was changed every 15 days. Large windows should be covered by black sheet to prevent direct sunlight rolling on the tanks.

The experiment was continued for 4 months starting from 15 September till 14 January. At the end of every month GSI \% were measured and gonads were processed in histological sections.

GSI was calculated using the following formula

GSI $=\frac{\text { Gonad weight }}{\text { Total Body weight }} \times 100$

(Albertine-Berhaut, 1973)

Ovaries and testis of fishes in treated and control were collected and subjected to histological 
techniques (Thulasitha and Sivashanthini, 2013). Histological photos were taken by using binocular light microscope equipped with camera (Olympus DP25, U-CMAD3). Microscope staging of gonads were assigned in to different maturity stages.

values of GSI were given as Mean \pm SE. Mean was tested for significant differences at $\mathrm{P}$-values $\leq 0.05$ (Duncan, 1955) to determine the effects of time period, and treatments. All the statistical analyses were calculated using SPSS program version 20 (SPSS, Richmond, USA) as described by Dytham (1999).

Table 1: The artificial photoperiod program throughout the study:

\begin{tabular}{|c|c|c|}
\hline Day No. & Lighting hours & Dark hours \\
\hline $1-15$ & 11 & 13 \\
\hline $16-30$ & $10: 45$ & $13: 15$ \\
\hline $31-45$ & $10: 30$ & $13: 30$ \\
\hline $46-60$ & $10: 15$ & $13: 45$ \\
\hline $61-75$ & $10: 30$ & $13: 30$ \\
\hline $76-90$ & $10: 45$ & $13: 15$ \\
\hline $91-105$ & 11 & 13 \\
\hline $106-120$ & 12 & 12 \\
\hline
\end{tabular}

\section{Results}

The effect of artificial photoperiod treatment on GSI \%:

Looking to table (2) GSI \% was significantly $(\mathrm{P} \leq 0.05)$ higher in female treated group at second and Third months when compared to control and the highest value was recorded in $\mathrm{T} 2$ after the third month $(1.36 \%)$ while in male treated group GSI was significantly $(\mathrm{P} \leq 0.05)$ higher at second month when compared to the control group. The highest value was 0.92 $\%$.
The effect of natural light on ovaries and testis maturity stages:

The histological sections of ovaries of $S$. aurata of control group $\left(\mathrm{T}_{1}\right)$ in immature stage showed oogonia and more spaces in sections with appearance of few primary oocytes (Photo 1) while the histological sections of $S$. aurata testis of control group $\left(T_{1}\right)$ showed many spermatogonia, sperm duct not visible and few spermatocytes were of immature stage (Photo 2). 
The effect of artificial photoperiod program on ovaries maturity stages $\left(\mathbf{T}_{2}\right)$ : -

The histological section of ovary in maturing stage after 1 month (stage II) showed primary growing phase with appearance of primary oocytes (oocytes in phase of nucleolus and perinucleolus). Primary oocytes were larger and increased in number with fewer oogonia than in control (Photo 3) and the histological section in maturing stage after 2 months (stage III) showed some oocytes beginning to undergo vitellogenesis with yolk granules on the cytoplasm and the oocytes were larger and more mature (Photo 4).

The histological section in maturing stage after 3 months (stage III) resemble the previous artichture with reducing on oocyte size (Photo 5). Section in maturing stage after 4 months (stage II) showed more spaces in section with few primary oocytes and more oogonia (Photo 6).

The effect of artificial photoperiod program on testis maturity stages $\mathbf{T}_{2}$ :

In maturing stage after 1 month (stage II) an increase in number of spermatocytes with the spermatogonia and sperm ducts more visible than in immature stage (Photo 7) and the histological section in maturing stage after 2 months (stage III) showed abundance of primary and secondary spermatocytes and few spermatogonia and spermatids (Photo 8). After 3 months (stage III) primary and secondary spermatocytes were fewer and few spermatids and spermatozoa were observed (Photo 9). The histological section of testis in immature stage after 4 months (stage II) showed few spermatocytes with beginning of spermatogonia (Photo 10).

Table 2: The effect of artificial photoperiod treatment on GSI \% in control and treated groups of male and female Gilthead sea bream:

\begin{tabular}{|c|c|c|c|c|}
\hline Gender & \multicolumn{2}{|c|}{ Female } & \multicolumn{2}{c|}{ Male } \\
\hline & T1 & T2 & T1 & T2 \\
\hline First month & $0.31 \pm 0.04$ & $0.71 \pm 0.02$ & $0.19 \pm 0.04$ & $0.45 \pm 0.05$ \\
\hline Second month & $0.40 \pm 0.07$ & $1.27 \pm 0.14^{\mathrm{a}}$ & $0.15 \pm 0.00$ & $0.92 \pm 0.21^{\mathrm{a}}$ \\
\hline Third month & $0.36 \pm 0.01$ & $1.36 \pm 0.08^{\mathrm{a}}$ & $0.20 \pm 0.02$ & $0.55 \pm 0.02$ \\
\hline Fourth month & $0.40 \pm 0.03$ & $0.87 \pm 0.20$ & $0.19 \pm 0.02$ & $0.36 \pm 0.04$ \\
\hline
\end{tabular}

Values are represented mean $\pm \mathrm{SE}$
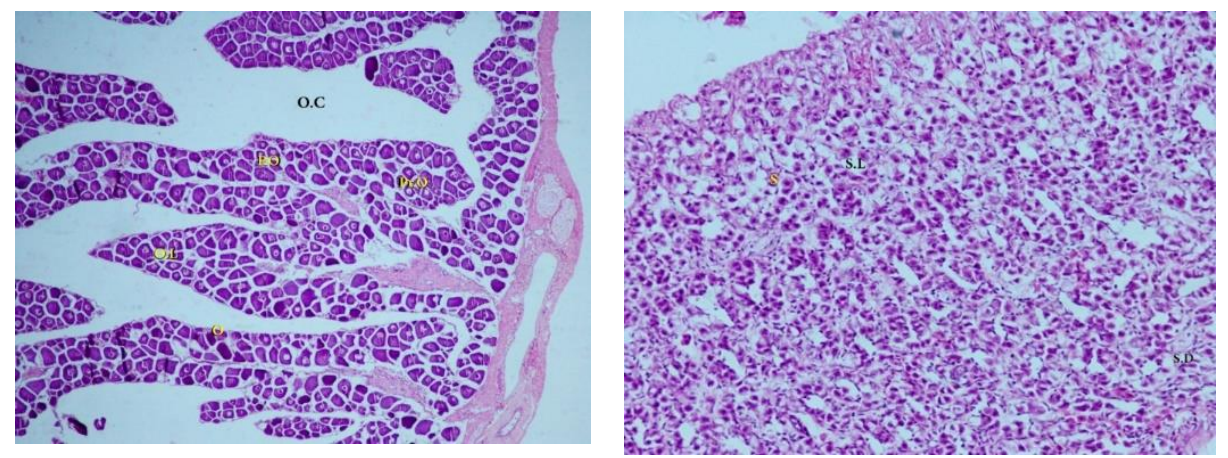
Photo 1: Histological section of S. aurata ovary (Control) in immature stage (I). O: oogonia, P.O: perinucleolar oocyte, O.C: ovarian Cavity, O.L: Ovarian lamella, Pr.O: Primary oocytes. H\&E stain. 4X.

Photo 2: Histological section of S. aurata testis (Control) in immature stage (I). S.L: Seminiferous Labules, S: Spermatogonia, S.D: Spermatic duct. H\&E Stain. 4X.
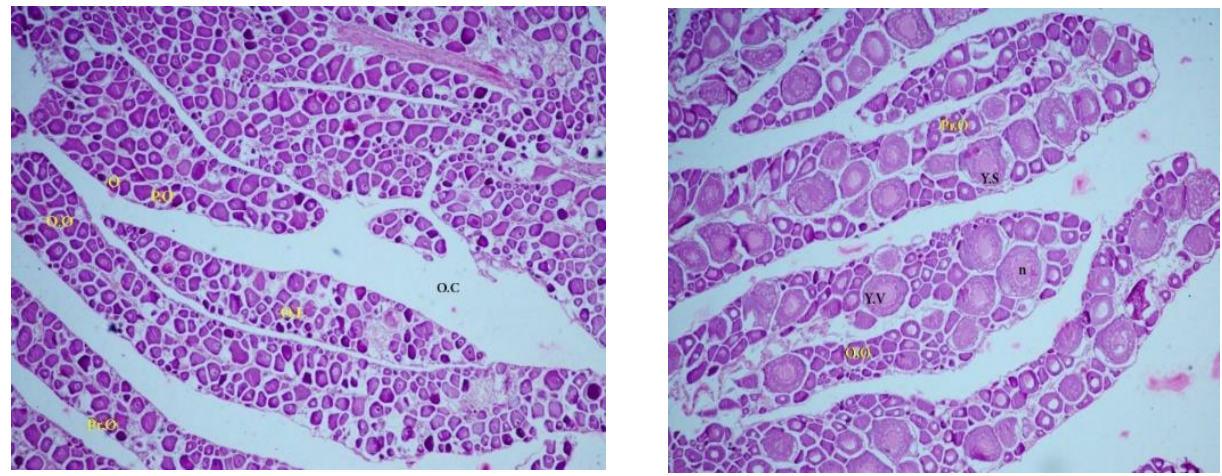

Photo 3: Histological section of S. aurata ovary in maturing stage. O: oogonia, P.O: perinucleolar oocyte, O.C: ovarian Cavity, O.L: Ovarian lamella, O.O: Oocytes in the phase of nucleolus, Pr.O: Primary oocytes. $\mathrm{H} \& \mathrm{E}$ stain. $4 \mathrm{X}$.

Photo 4: Histological section of S. aurata ovary in maturing stage. O.C: ovarian Cavity, O.O: oocytes in the phase of nucleolus, Pr.O: Primary oocytes, Y.s: Vitellogenic granules, Y.V: yolk vesicle. H\&E stain. 4X.
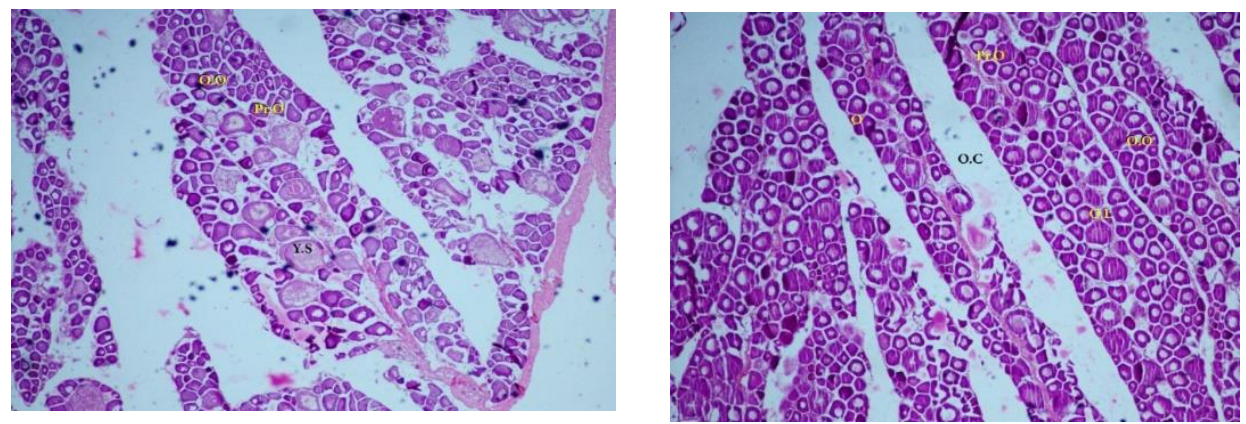

Photo 5: Histological section of S. aurata ovary in maturing stage slightly like stage. O.O: oocytes in the phase of nucleolus, Pr.O: Primary oocytes, Y.S: Vitellogenic granules. H\&E stain. 4X.

Photo 6: Histological section of S. aurata ovary in maturing stage slightly like stage. O: oogonia, P.O: perinucleolar oocyte, O.C: ovarian Cavity, O.L: Ovarian lamella, O.O: oocytes in the phase of nucleolus, Pr.O: Primary oocytes. H\&E stain. 

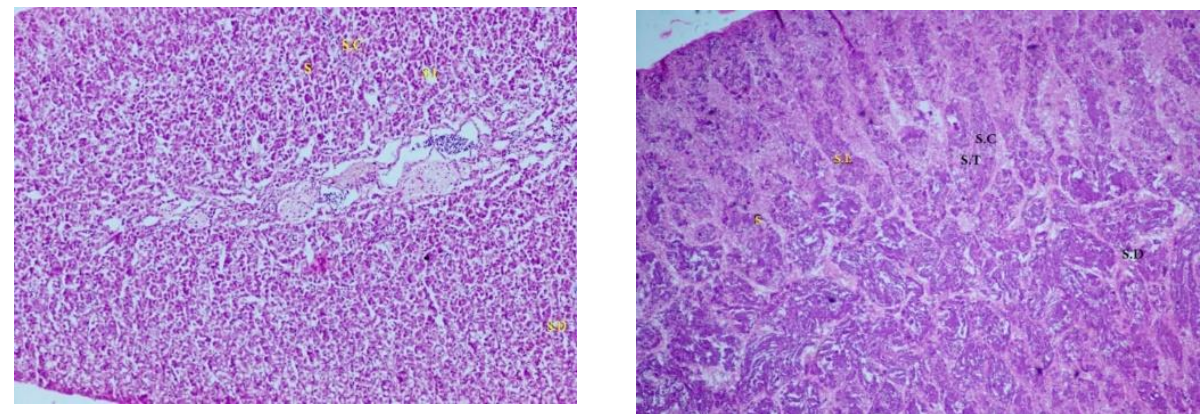

Photo 7: Histological section of $\mathrm{S}$. aurata testis in maturing stage (II) of $\mathrm{S}$. aurata testis. S.L: Seminiferous Tubules, S: Spermatogonia, S.D: Spermatic duct, S.C: spermato cytes. H\&E Stain. 4X.

Photo 8: Histological section of S. aurata testis in maturing stage (III). S.L: Seminiferous Tubules, S: Spermatogonia, S.D: Spermatic duct, S.C: spermato cytes, S.T: spermatids. H\&E Stain. 4X.
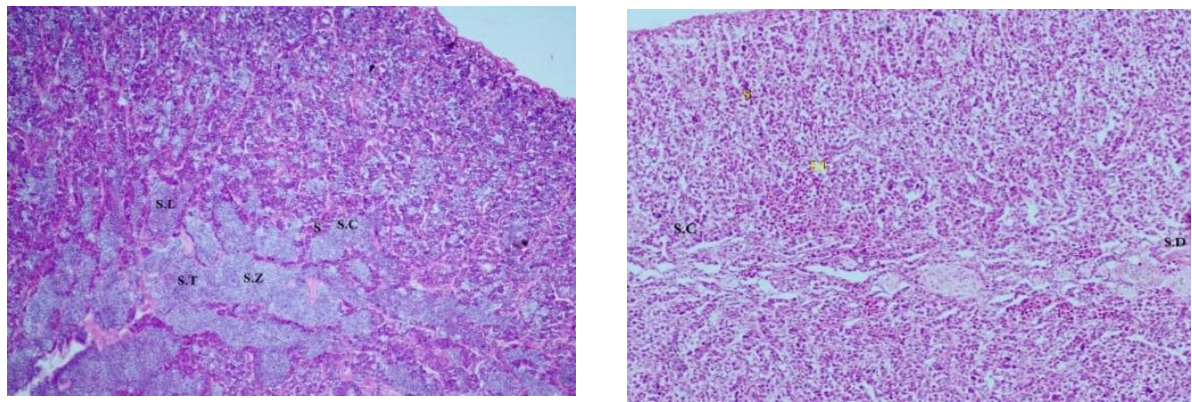

Photo 9: Histological section of S. aurata testis in maturing stage slightly like stage (III). S.L: Seminiferous Tubules, S: Spermatogonia, S.D: Spermatic duct, S.C: spermato cytes, S.T: spermatids, S.Z: Spermatozoa. H\&E Stain. $4 X$.

Photo 10: Histological section of S. aurata testis in maturing stage slightly like stage (II). S.L: Seminiferous Tubules, S: Spermatogonia, SD: Spermatic duct, S.C: spermato cytes. H\&E Stain

\section{Discussion}

GSI (\%) showed the peak value in group 2 at third month for female and at second month for male (Table 2). The highest values recorded for GSI \% may be related to gonadal weight which become large and filled with eggs approaching spawning season during December. These results 
were in agreement with Mehanna (2007) who reported monthly variation in GSI values and the distribution of different maturity stages revealed that the spawning activity continued from month September till month January when artificial light program is used. It is familiar that GSI increases with the maturation of fish being maximum during the period of peak maturity (December) then decline after that. These results were in agreement with Parween et al., (1993).

Results confirmed that gonadal development, maturation stages and the changes in reproductive cycle in gilthead sea bream broodstocks may be controlled by artificial photoperiod programs that triggered hypothalamus-pituitary-gonad (HPG) axis to start and initiate the reproductive cycle $(\mathbf{L i}$, et al., 2015 and Franz and Manfred, 2012). Increasing in GSI \% observed in this study may be attributed to increasing the level of FSH and LH after the second and third month. Photoperiod has been the primary hint to HPG axis to start the reproductive cycle but it can't trigger this axis to complete the maturation, spermiation and ovulation. This dataset demonstrated that water temperature program has the greater effect on maturation. These results largely confirmed by the findings of Badran, (2015) who reported that under artificial photoperiod and water temperature program for 4 months gilthead sea bream reached to final maturation and released eggs but in different quality and quantity.

Increasing FSH levels might have a role on producing of oogenesis, primary and secondary oocytes and undergo vitellogenesis with yolk granules in female and primary spermatogenesis in male that observed in histological sections. These results are confirmed by the findings of (Rainis et al., 2003 and Yousefian and Mousavi, 2011).

Artificial photoperiod program $\left(\mathrm{T}_{2}\right)$ inducing gradual increasing in GSI values starting from the first month $0.71 \%$ till reach the peak in the third month $1.36 \%$ then decreased rapidly after the fourth month in female. In male GSI values were increased from the first month 0.45 $\%$ till reach the peak in the second month $0.92 \%$ then decreased rapidly until the fourth month. The current histological sections of ovaries in maturing stage showed primary growing phase with appearance of primary oocytes larger in size and increasing the number of nucleolus and perinucleolus oocytes with fewer oogonia. In maturing stage after the second month, some oocytes begin to undergo vitellogenesis with yolk granules on the cytoplasm and the oocytes become larger and more mature. The third section of ovary was like the last section with reducing oocyte size while the fourth section in maturing stage is nearly similar to the first section that showed more spaces in section 
with few primary oocytes and more oogonia. These findings were similar to the findings of Shinkafi, et al., (2011).

The histological sections of testis in the artificial photoperiod program treatment $\left(\mathrm{T}_{2}\right)$ showed that the first section in maturing stage that showed more spermatocytes with the spermatogonia and sperm ducts that become visible than in immature stage. The second section showed primary and secondary spermatocytes more in abundance and few spermatogonia and spermatids. The third section of testis showed fewer primary and secondary spermatocytes than the last section and few spermatids and spermatozoa while the fourth section in maturing stage nearly similar to the first section stage with few spermatocytes and beginning of spermatogonia and few spermatozoa in sperm duct. These findings were similar to the findings of Shinkafi, et al., (2011).

Photoperiod has been thought to be the primary cue, in maturation. During photoperiod treatment smaller oocytes; mostly previtellogenic oocytes filled with lipid droplets without accumulation of yolk granules was observed in histological sections (photo. 3, 4, 5 and 6) in female. In male under photoperiod treatment histological sections showed signs of reproductive abnormalities especially after fourth month. This may be a result of a disruption in spermatogenesis (Strait, 2006). The effect of light in fish maturation is due to its major initiating and synchronizing environmental stimulus for reproduction. The consensus is that the seasonal cycle of changing light and darkness is used as a predictive tool due to initiate gametogenesis (Angus et al., 1990).

Conclusion: From the present results it could be concluded that photoperiod program is considered the primary hint to start the reproductive cycle and gonadal maturation but it couldn't reach the final maturity and can induce spawning of gilthead sea bream in captivity.

\section{References}

Albertine-Berhaut, J., (1973). Biologie des stades juveniles detéleostéens Mugilidae Mugil auratus Risso 1810, Mugil capito Cuvier 1829 et Mugil saliens Risso 1810: I. Régime alimentaire. Aquaculture 2, 251266.

Angus D. M., Alexander P. S., and Lam T. J., (1990). Reproductive seasonality in teleosts: environmental influences. United states. CRC press, inc. P:135- 136.

Arabaci, M. and Yilmaz, Y., (2010). A Review on population characteristics of Gilthead seabream (Sparus aurata). Journal of Animal and Veterinary Advances 9 (6) 976 -981 . 
Badran M. F. (2015). Studies on Reproduction of Marine Fish. Master thesis, Fac. Agri. Sci. Suez Canal University, 27-48 pp.

Duncan, D B. (1955). Multiple range and multiple $F$ tests. Biometrics 11:1-42,

Dytham, C., (1999). Choosing and using statistics: a biologist's guide Blackwell Science Ltd, London, UK

FAO, (1999). Manual on Hatchery Production of Sea bass and Sea bream, Roma. Vol 1. pp: 5- 14

FAO, (2005). Manual on Hatchery Production of Sea bass and Sea bream, Roma. Vol 2 . pp: 10- 20

Franz, L. and Manfred, K. (2012). The effect of water temperature on gamete maturation and gamete quality in the European grayling (Thymalus thymallus) based on experimental data and on data from wild populations. Fish Physiology and Biochemistry 38, 455-467.

Li, G. L., Zhang, M.Z., Deng, S.P., Chen, H.P., and Zhu, C.H., (2015). Effects of temperature and fish oil supplementation on ovarian development and foxl2 mRNA expression in spotted scat

Scatophagus argus.

Journal of Fish Biology (2015) 86, 248-260.

Mehanna S.F. (2007). A preliminary assessment and management of gilthead bream Sparus aurata in the Port Said fishery, the southeastern Mediterranean, Egypt. Turkish J. Fish. Aquat. Sci. 7: 123-130.
Muncaster S., Pether S.M.J., Van de Ven I., Marchant A., Irvine G., Johnson S.L., Rosengrave P., Lokman P.M. and J.E. Symonds (2013).

Gonadotropinreleasing Hormone Implants Induce Spawning in Female Yellowtail Kingfish Seriola lalandi. World Aquaculture.

U.S.

Aquaculture Society. P: $42-44$.

Parween, S., Begum, N., Rahman, M.H. and Hossain, M.A., (1993). On the breeding periodicity of Esomus danricus (Hamilton). Univ. J. Zool. Rajshahi Univ., 12:31-34

Rainis, S., Mylonas CC., Kyriakou $Y$, and Divanach $P$. (2003). Enhancement of spermiation in European sea bass (Dicentrarchus labrax) at the end of the reproductive season using GnRHa implants. Aquaculture, 219: 873- 890.

Shinkafi B. A., Ipinjolu J. K. and Hassan W. A., (2011). Gonad maturation stages of Auchenoglanis occidentalis (Valenciennes 1840) in River Rima, North-Western Nigeria. Journal of Fisheries and Aquatic Sciences 6 (3):236-246.

Strait, K. (2006). "The effects of photoperiod and water temperature on the reproductive development of black sea bass, Centropristis striata" Master's Theses and Capstones. 248.

Thulasitha, W. S., and Sivashanthini. K.,(2013). Microscopic Staging Sysytem used in the Identification of Gonads Development Stages of Scomberoides lysan. Journal of 
Fisheries and Aquatic Science 8(2): in finfish species: A review. 355-366.

Scientific Research and

Yousefian, M., and Mousavi, S., Essays Vol. 6(17), pp. 3561-3570, E., (2011). The mechanism of reproduction and hormonal function

ISSN 1992-2248

(C)2011

Academic Journals

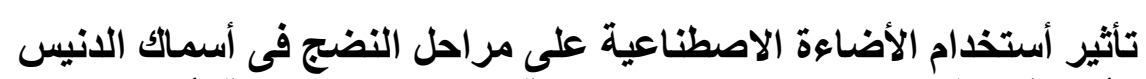

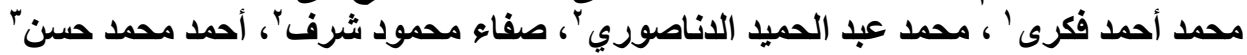

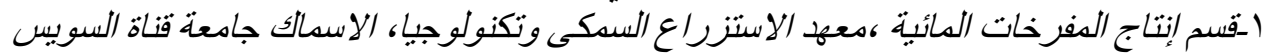

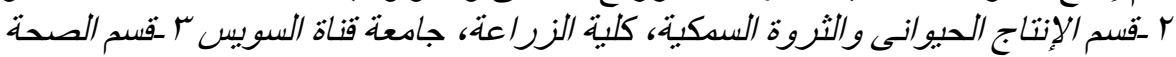
والامراض المثتركة، كلية الطب البيطري، جامعة قناة السويس النيس

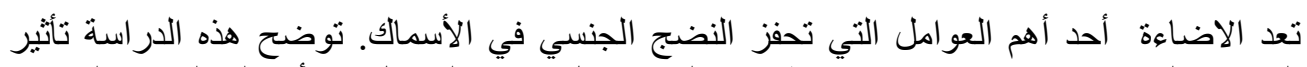

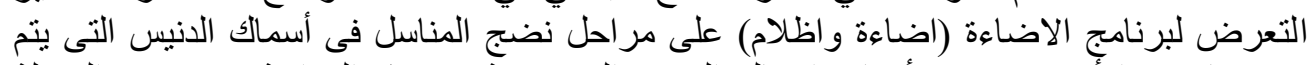

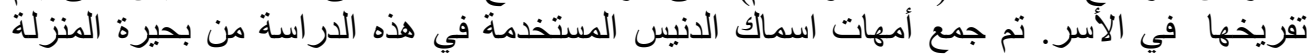

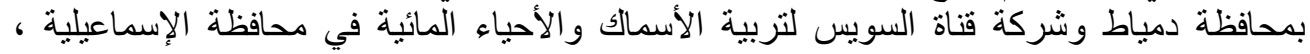

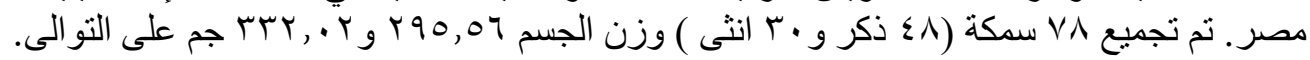

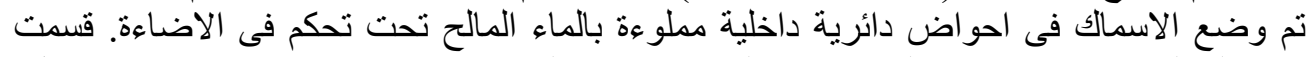

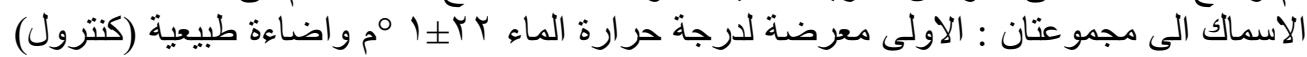

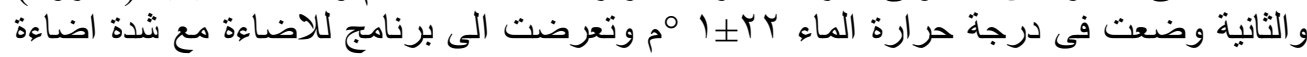

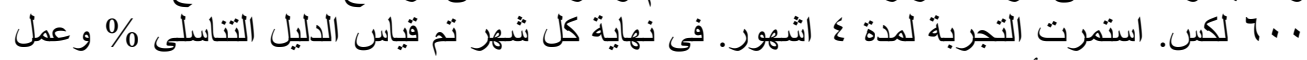

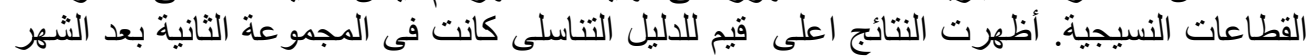

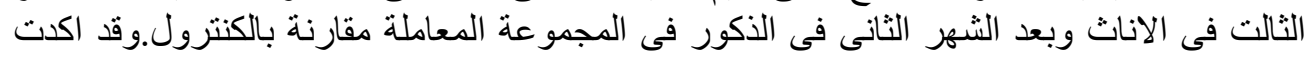

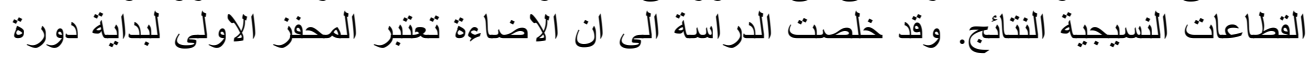

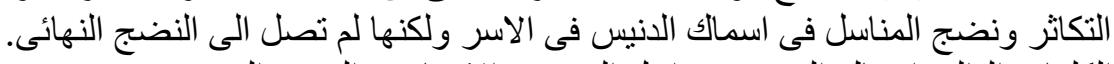

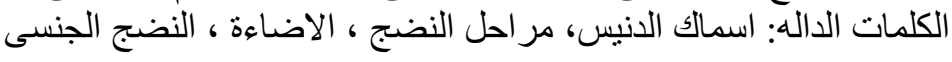

